\title{
Who benefits most from mild therapeutic hypothermia in coronary intervention era? A retrospective and propensity-matched study
}

Eisuke Kagawa*, Ichiro Inoue, Takuji Kawagoe, Masaharu Ishihara, Yuji Shimatani, Satoshi Kurisu, Yasuharu Nakama, Kazuoki Dai, Takayuki Otani, Hiroki Ikenaga, Yoshimasa Morimoto, Kentaro Ejiri, Nozomu Oda

\begin{abstract}
Introduction: The aim of the present study was to investigate the impact of the time interval from collapse to return of spontaneous circulation (CPA-ROSC) in cardiac arrest patients and the types of patients who will benefit from therapeutic hypothermia.

Methods: Four hundred witnessed adult comatose survivors of out-of-hospital cardiac arrest of cardiac etiology were enrolled in the study. The favorable neurological outcome was defined as category 1 or 2 on the five-point Pittsburgh cerebral performance scale at the time of hospital discharge. A matching process based on the propensity score was performed to equalize potential prognostic factors in the hypothermia and normothermia groups, and to formulate a balanced 1:1 matched cohort study.

Results: The rate of favorable neurological outcome was higher $(P<0.05)$ in the hypothermia group $(n=110)$ than in the normothermia group in patients with CPA-ROSC of 15 to 20 minutes (64\% vs. 17\%), 20 to 25 minutes (70\% vs. $8 \%$ ), 25 to 30 minutes ( $50 \%$ vs. $7 \%$ ), 35 to 40 minutes ( $27 \%$ vs. $0 \%$ ) and 40 to 45 minutes (29\% vs. $2 \%$ ). A similar association was observed in a propensity-matched cohort, but the differences were not significant. There was no significant difference in the rate of favorable neurological outcome between the hypothermia-matched group and the normothermia-matched group. In the patients whose CPA-ROSC was greater than 15 minutes, however, the rate of favorable neurological outcome was higher in the hypothermia-matched group than in the normothermia-matched group ( $27 \%$ vs. $4 \%, P<0.001)$. In multivariate analysis, the CPA-ROSC was an independent predictor of favorable neurological outcome (every 1 minute: odds ratio $=0.89,95 \%$ confidence interval $=0.85$ to $0.92, P<0.001)$.
\end{abstract}

Conclusions: The CPA-ROSC is an independent predictor of neurological outcome. Therapeutic hypothermia is more beneficial in comatose survivors of cardiac arrest with CPA-ROSC greater than 15 minutes.

\section{Introduction}

Cardiac arrest has a poor prognosis and is a major cause of unexpected death in developed countries. Despite cardiopulmonary resuscitation (CPR), only a few patients fully resume their former lifestyle, mainly because of anoxic brain injury [1,2]. Mild therapeutic hypothermia (MTH) improves neurological outcome in comatose survivors of cardiac arrest $[3,4]$. Previous studies have reported that coronary reperfusion therapy with

\footnotetext{
* Correspondence: ekagawa@za2.so-net.ne.jp

Department of Cardiology, Hiroshima City Hospital, 7-33 Moto-machi, Nakaku, Hiroshima 730-8518, Japan
}

percutaneous coronary intervention improves outcomes in out-of-hospital cardiac arrest (OHCA) patients [5-8]. The frequency of MTH is increasing in clinical settings; however, little is known about the types of patients who will benefit neurologically from $\mathrm{MTH}$, will be able to resume their former lifestyle, and should not be treated with MTH [9].

The time interval from collapse to return of spontaneous circulation (ROSC) has been reported to be a strong independent predictor of neurological outcome in comatose survivors of cardiac arrest [4,10-14]. We therefore investigated the impact of the time interval 
from collapse to ROSC (CPA-ROSC) in OHCA patients treated with and without MTH.

\section{Materials and methods Study patients}

We retrospectively enrolled witnessed adult ( $>18$ years of age) OHCA patients with cardiac causes transported to Hiroshima City Hospital, who achieved ROSC and who were comatose between September 2003 and January 2010. All OHCA patients were treated in accordance with an advanced cardiac life support protocol, and the patients who met the criteria for hypothermia treatment were treated with MTH as reported previously [10]. MTH was fundamentally induced in cardiac arrest patients with presumed cardiac origin and the following criteria [15]: age 18 to 79 years, and an estimated interval of less than 15 minutes from collapse to the first attempt at resuscitation by any person.

Before 2006, an assessment of cardiac arrest complicated by ischemic heart disease was made in patients treated with and without MTH. In patients with suspected acute coronary syndrome, emergency coronary angiography or percutaneous coronary intervention, or both, were subsequently performed. After 2006, routine emergency coronary angiography was performed in patients treated with MTH.

The present study was approved by the local ethics committee on human research and is conducted in accordance with the guidelines of the Declaration of Helsinki. All data were collected within the normal daily care routine in an anonymous fashion. The institutional review board therefore waived the need for informed patient consent.

\section{Hypothermia protocol}

$\mathrm{MTH}$ was induced in comatose survivors using a surface cooling mattress and the administration of physiological saline $\left(4^{\circ} \mathrm{C}\right)$ as reported previously [10]. Before January 2008 , the target temperature was set between $32^{\circ} \mathrm{C}$ and $34^{\circ} \mathrm{C}$ (fundamentally, $33^{\circ} \mathrm{C}$ ) and was maintained for 48 hours followed by rewarming at $0.5^{\circ} \mathrm{C}$ every 12 hours. After January 2008, the core temperature was maintained for 24 hours and rewarming continued for 12 hours.

\section{Data collection}

The primary endpoint was a favorable neurological outcome, which is defined as category 1 (good performance) or category 2 (moderate disability) on the fivepoint Pittsburgh cerebral performance scale; the other categories are 3 (severe disability), 4 (vegetative state), and 5 (death) at the time of hospital discharge [16].

\section{Statistical analysis}

Continuous variables are presented as medians (with interquartile ranges), and categorical variables are presented as numbers and percentages. Differences between groups at baseline were analyzed using the MannWhitney $U$ test for continuous variables and a chi-square test or Fisher's exact test for categorical variables as appropriate. The rate of favorable neurological outcome was plotted against the CPA-ROSC every 5 minutes for patients treated with and without MTH. We used Fisher's exact test to access differences in the rate of favorable neurological outcomes every 5 minutes between the groups.

To detect favorable neurological outcome, we constructed receiver-operating characteristic curves for the CPA-ROSC.

The threshold for performing MTH was set high early in the study period. For example, we induced MTH only in comatose survivors whose initial rhythm indicated ventricular fibrillation. Because the patients were not randomly assigned to receive $\mathrm{MTH}$ or normothermia, potential confounding and selection biases were accounted for by developing a propensity score. The propensity for MTH or not was determined without regard to the outcome using a multivariate regression model. For this model, we chose variables we thought might increase the propensity for MTH over normothermia therapy, which included age, Pittsburgh overall performance category score before cardiac arrest, initial rhythm, the time interval from collapse to start of CPR and the CPA-ROSC. This model yielded a concordance statistic of 0.80 , which indicated good discrimination. A propensity score was then calculated from the logistic equation for each patient, which indicated the probability that a patient would be treated with MTH. All study patients were pooled and sorted according to their propensity scores in the ascending order and a propensity-matched cohort was formed [17].

A logistic regression model was used to examine the association between the CPA-ROSC and favorable neurological outcome in an unadjusted model, in a model adjusted for age, gender, and initial rhythm, and in a model adjusted for age, gender, Pittsburgh overall performance category score, initial rhythm, time interval from collapse to start of CPR, hypertension, diabetes mellitus, history of heart disease, emergency coronary angiography, primary percutaneous coronary intervention, use of intra-aortic balloon pump, use of extracorporeal life support, admission after 2006 and propensity score.

The JMP statistical package (version 5.0.1 J; SAS Institute, Cary, NC, USA) and R version 2.9.2 [18] were used 
for statistical analyses. All tests were two-sided, and P < 0.05 was considered statistically significant.

\section{Results}

\section{Patient characteristics}

A flow diagram of the study patients and their outcomes is depicted in Figure 1. Witnessed adult comatose survivors of OHCA $(n=400)$ with cardiac causes were enrolled in the study. The baseline clinical characteristics, treatment and findings for study patients are shown in Tables 1 and 2. One hundred and ten patients (28\%) were treated with MTH (hypothermia group) and 290 patients were treated without MTH (normothermia group). There were many differences in baseline characteristics between these groups. The normothermia group was in a more severe condition for resuscitation.

\section{Outcomes}

The outcomes of the study patients are shown in Table 3 . The rate of favorable neurological outcome (39\% vs. $14 \%, P<0.001)$ and 30 -day survival $(48 \%$ vs. $16 \%, P<$
0.001) were higher in the hypothermia group than in the normothermia group. The CPA-ROSC in patients with a favorable neurological outcome was longer $(P<$ 0.001 ) in the hypothermia group (median, 22 minutes; interquartile range, 16 to 32 minutes; mean \pm standard deviation, $25 \pm 13$ minutes) than in the normothermia group (median, 11 minutes; interquartile range, 5 to 14 minutes; mean \pm standard deviation, $12 \pm 8$ minutes).

The rate of favorable neurological outcome was plotted against the CPA-ROSC every 5 minutes (Figure 2 ). In the hypothermia group, the rate of favorable neurological outcome decreased in a stepwise fashion when the CPA-ROSC was longer than 25 minutes. In the normothermia group, the rate of favorable neurological outcome decreased remarkably when the CPA-ROSC was longer than 15 minutes, and none of the patients whose CPA-ROSC was longer than 45 minutes had a favorable neurological outcome. The rate of favorable neurological outcome was significantly higher in the hypothermia group than in the normothermia group in patients with a CPA-ROSC of 15 to 20 minutes (64\% vs. $17 \%, P<$

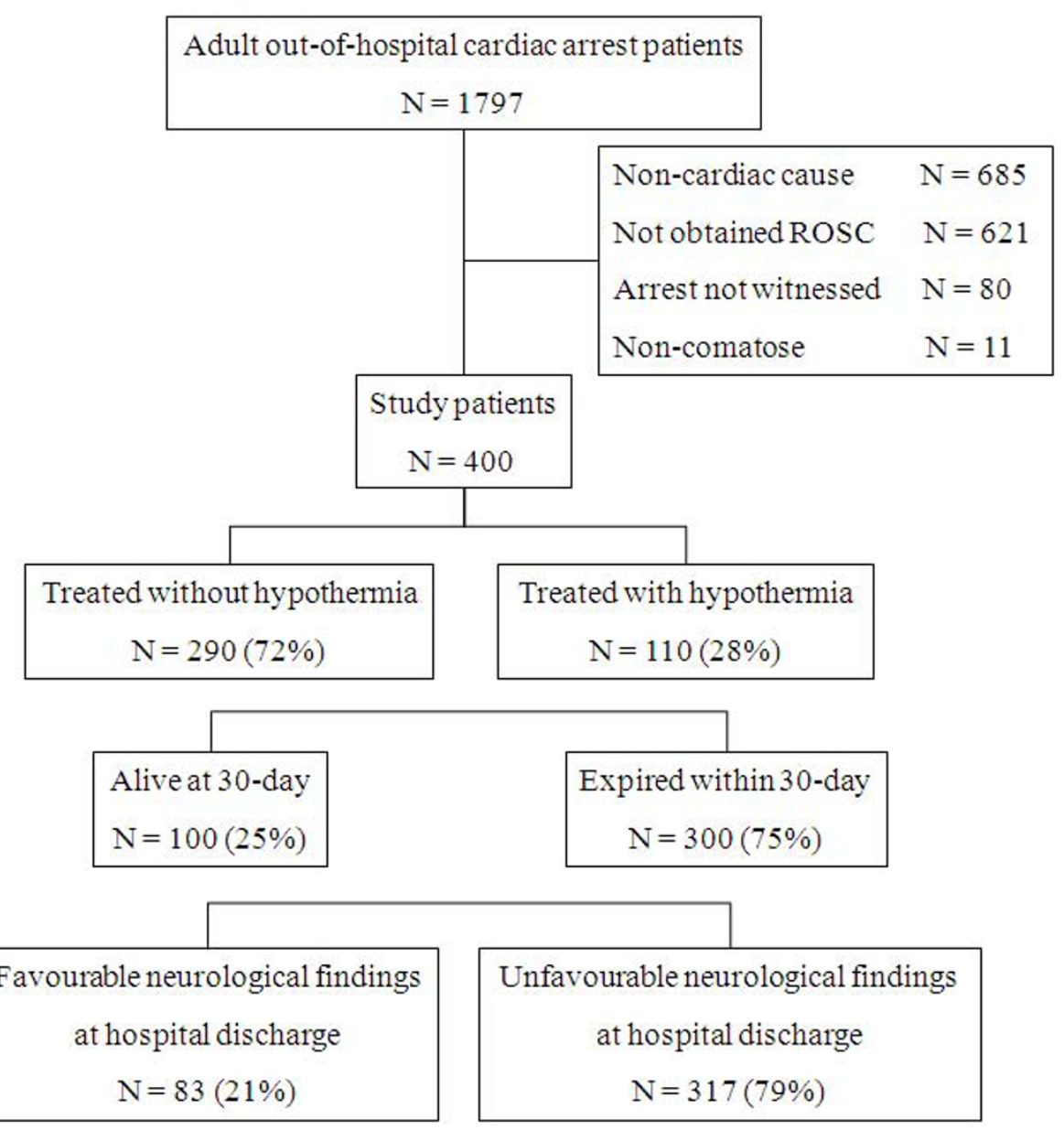

Figure 1 Flow diagram of study patients and outcomes. ROSC, return of spontaneous circulation. 
Table 1 Baseline clinical characteristics of the study patients

\begin{tabular}{|c|c|c|c|}
\hline & $\begin{array}{l}\text { Hypothermia group }(n= \\
\text { 110) }\end{array}$ & $\begin{array}{l}\text { Normothermia group }(n= \\
\text { 290) }\end{array}$ & $\begin{array}{l}P \\
\text { value }\end{array}$ \\
\hline Age (years) & 55 (46 to 68) & 74 (62 to 83$)$ & $<0.001$ \\
\hline Male gender & $90(82)$ & $177(61)$ & $<0.001$ \\
\hline Pittsburgh overall performance category scale before index cardiac arrest & & & $<0.001$ \\
\hline Category 1 & $109(99)$ & $216(74)$ & \\
\hline Category 2 & $1(1)$ & $62(21)$ & \\
\hline Category 3 & $0(0)$ & $12(4)$ & \\
\hline Category 4 & $0(0)$ & $0(0)$ & \\
\hline Initial rhythm & & & $<0.001$ \\
\hline Ventricular fibrillation & $64(58)$ & $41(14)$ & \\
\hline Pulseless electrical activity & $23(21)$ & $134(46)$ & \\
\hline Asystole & $23(21)$ & $115(40)$ & \\
\hline Bystander cardiopulmonary resuscitation & $61(55)$ & $137(47)$ & 0.14 \\
\hline $\begin{array}{l}\text { Time interval from collapse to start of cardiopulmonary resuscitation } \\
\text { (minutes) }\end{array}$ & $6(1$ to 10$)$ & $7(1$ to 14$)$ & 0.049 \\
\hline Time interval from collapse to return of spontaneous circulation (minutes) & 35 (21 to 48$)$ & $43(23$ to 56$)$ & $<0.01$ \\
\hline Admission after 2006 & $83(75)$ & $169(58)$ & $<0.01$ \\
\hline Hypertension & $44(40)$ & $85(29)$ & 0.04 \\
\hline Diabetes mellitus & $29(26)$ & $47(16)$ & 0.02 \\
\hline Previous history of heart disease & $42(38)$ & $63(22)$ & $<0.001$ \\
\hline Previous history of myocardial infarction & $18(16)$ & $15(5)$ & $<0.001$ \\
\hline Previous history of chronic heart failure & $16(15)$ & $27(9)$ & 0.13 \\
\hline \multicolumn{4}{|l|}{ Cause of cardiac arrest } \\
\hline Acute coronary syndrome & $46(41)$ & $56(19)$ & \\
\hline Old myocardial infarction & $12(11)$ & $4(1)$ & \\
\hline Cardiomyopathy & $13(12)$ & $8(3)$ & \\
\hline Spasm of coronary artery & $8(7)$ & $2(1)$ & \\
\hline Others & $27(25)$ & $72(25)$ & \\
\hline Unknown & $4(4)$ & $148(51)$ & \\
\hline
\end{tabular}

Data presented as median (interquartile range) or $n(\%)$.

Table 2 In-hospital treatment and findings in the study patients

\begin{tabular}{|c|c|c|c|}
\hline & $\begin{array}{l}\text { Hypothermia group }(n= \\
110)\end{array}$ & $\begin{array}{l}\text { Normothermia group }(n= \\
\text { 290) }\end{array}$ & $\begin{array}{l}P \\
\text { value }\end{array}$ \\
\hline Dose of epinephrine (mg) & 1 (0 to 3$)$ & $1(0$ to 2$)$ & 0.54 \\
\hline Emergency coronary angiography & $68(62)$ & $34(12)$ & $<0.001$ \\
\hline Primary percutaneous coronary intervention & $33(30)$ & $16(6)$ & $<0.001$ \\
\hline Use of intra-aortic balloon pump & $65(59)$ & $22(8)$ & $<0.001$ \\
\hline Use of extracorporeal life-support & $27(25)$ & $13(4)$ & $<0.001$ \\
\hline $\begin{array}{l}\text { Time interval from return of spontaneous circulation to target temperature } \\
\text { (minutes) }\end{array}$ & 149 (104 to 262$)$ & & \\
\hline Protocol of duration of cooling/rewarming 24 hours/12 hours & $40(36)$ & & \\
\hline Duration of cooling (hours) & 47 (24 to 49$)$ & & \\
\hline Duration of rewarming (hours) & 47 (17 to 57$)$ & & \\
\hline Duration of hospital stay (days) & 17 (5 to 29$)$ & 1 (1 to 3$)$ & $<0.001$ \\
\hline \multicolumn{4}{|l|}{ Cause of death within 30 days } \\
\hline Hemodynamic instability & $21(36)$ & $90(37)$ & \\
\hline Withdrawal of intensive therapy & $18(32)$ & $85(35)$ & \\
\hline Multiple organ failure & $15(26)$ & $10(4)$ & \\
\hline Pneumonia & $3(6)$ & $12(5)$ & \\
\hline Other & $0(0)$ & $46(19)$ & \\
\hline
\end{tabular}




\begin{tabular}{lll}
\hline & Hypothermia group $(\boldsymbol{n}=\mathbf{1 1 0})$ & Normothermia group $(\boldsymbol{n}=\mathbf{2 9 0})$ \\
\hline Favorable neurological outcome & $43(39)$ & $40(14)$ \\
Good cerebral performance & $42(38)$ & $39(13)$ \\
Moderate cerebral disability & $1(1)$ & $1(1)$ \\
Severe cerebral disability & $0(0)$ & $1(1)$ \\
Coma or vegetative state & $8(7)$ & $8(3)$ \\
Dead & $59(54)$ & $241(82)$ \\
Thirty-day survival & $53(48)$ & $47(16)$ \\
\hline
\end{tabular}

Data presented as $n$ (\%).

0.01), 20 to 25 minutes ( $70 \%$ vs. $8 \%, P<0.01$ ), 25 to 30 minutes (50\% vs. $7 \%, P=0.02)$, 35 to 40 minutes (27\% vs. $0 \%, P=0.03)$ and 40 to 45 minutes $(29 \%$ vs. $2 \%, P=$ 0.049 ). There was a trend toward a higher rate of favorable neurological outcome in the hypothermia group than in the normothermia group in patients in whom the CPA-ROSC was 30 to 35 minutes $(27 \%$ vs. $0 \%, P=$ $0.08)$. The rate of favorable neurological outcome was similar in patients with a CPA-ROSC less than 15 minutes.

Receiver-operating characteristic curves of the CPAROSC to detect favorable neurological outcome are shown in Figure 3. The areas under the receiver-operating characteristic curve were 0.79 (95\% confidence interval $(\mathrm{CI})=0.68$ to 0.86$)$ and $0.95(95 \% \mathrm{CI}=0.92$ to 0.98$)$ in the hypothermia and normothermia groups, respectively. The cut-off values for the CPA-ROSC of 29 minutes in hypothermia group and 15 minutes in the normothermia group had the highest combined sensitivity and specificity, with accuracy of $75.4 \%$ and $92.8 \%$ for identifying favorable neurological outcomes, respectively (Table 4). A long CPA-ROSC was associated with more accurate negative predictive values.

\section{Propensity matched analysis}

The propensity score-matching process selected 79 patients from the hypothermia group (hypothermia-M group) and 79 patients from the normothermia group (normothermia-M group). The mean \pm standard deviation propensity score was $0.41 \pm 0.22$ in the hypothermia-M group and was $0.41 \pm 0.22$ in the normothermia-M group $(P=0.94$; Figure 4$)$. Propensitymatched patient characteristics, treatments and outcomes are presented in Table 5. Baseline characteristics were similar in the two groups except for emergency coronary angiography, primary percutaneous coronary intervention, use of intra-aortic balloon pump and use of extracorporeal circulation. In patients with a favorable neurological outcome, the CPA-ROSC was significantly longer $(P<0.001)$ in patients in the hypothermia-M group (median, 22 minutes; interquartile range, 16 to 31 minutes; mean \pm standard deviation, $25 \pm 12$ minutes) than those in the normothermia- $M$ group (median, 10 minutes; interquartile range, 5 to 13 minutes; mean \pm standard deviation, $11 \pm 9$ minutes).

The rate of favorable neurological outcome was plotted against the CPA-ROSC every 5 minutes in the propensity-matched cohort (Figure 5). An association similar to the full cohort (Figure 2) was observed in the propensity-matched cohort, but the difference was not statistically significant and might be caused from the small sample size of the study. There was no significant difference in the rate of favorable neurological outcome between the hypothermia-M group and the normothermia-M group in the entire propensity-matched cohort (30\% vs. $29 \%, P=0.86$ ). In patients whose CPA-ROSC was more than 15 minutes, however, the rate of favorable neurological outcome was higher in the hypothermia-M group than in the normothermia-M group $(27 \%$ vs. $4 \%, P<0.001)$.

\section{Predictor of neurological outcome}

In the full cohort, we tested the association between the CPA-ROSC and favorable neurological outcome in multiple models. In an unadjusted model, there was a significant association between the CPA-ROSC and favorable neurological outcome (every 1 minute: odds ratio = $0.90,95 \% \mathrm{CI}=0.88$ to $0.92, P<0.001)$. After adjustment for age, gender, and initial rhythm, this association was still significant (odds ratio $=0.89,95 \% \mathrm{CI}=0.86$ to 0.92 , $P<0.001)$. Finally, after adjustment for all of the abovementioned variables, the association between the CPAROSC and favorable neurological outcome remained significant (odds ratio $=0.89,95 \% \mathrm{CI}=0.85$ to $0.92, P<$ 0.001).

\section{Discussion}

We showed that the CPA-ROSC is a strong independent predictor of favorable neurological outcome in the present $\mathrm{MTH}$ era, and that MTH prolongs the maximum CPA-ROSC to obtain a favorable neurological outcome. $\mathrm{MTH}$ is more beneficial in OHCA patients with a CPAROSC longer than 15 minutes in terms of neurological outcome. 
(a)

\section{Hypothermia group}

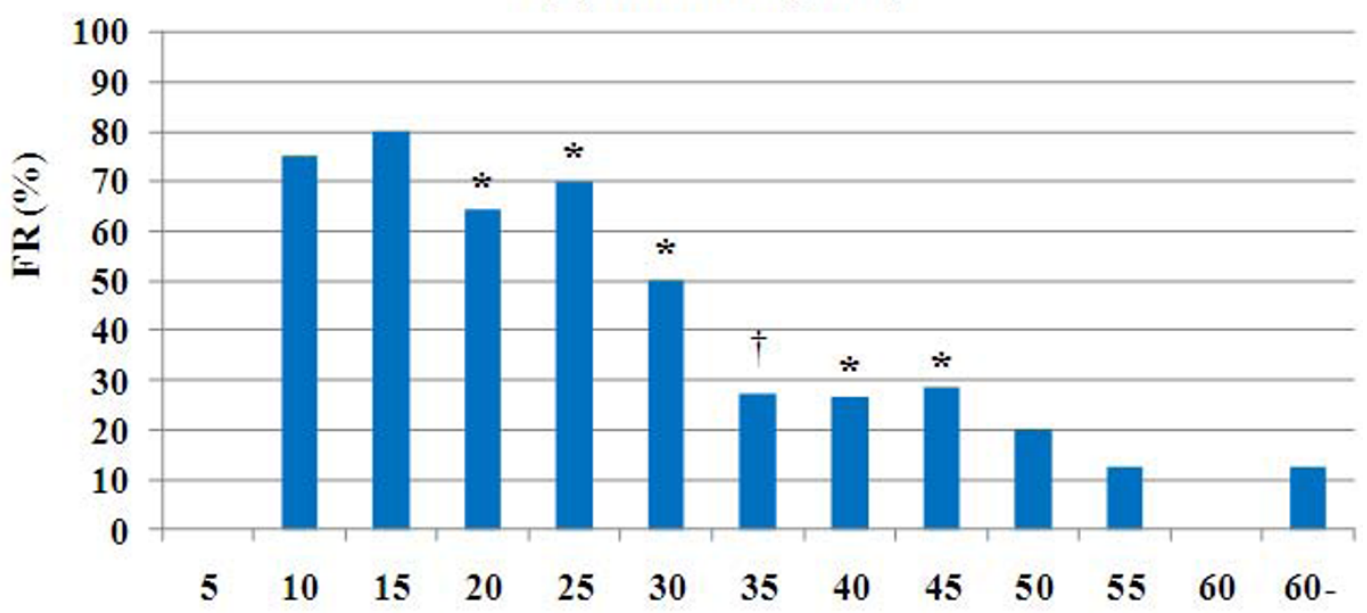

No. of patients

CPA-ROSC (min)

$\begin{array}{clllllllllllll}\text { FR } & 0 & 6 & 4 & 9 & 7 & 5 & 3 & 4 & 2 & 1 & 1 & 0 & 1 \\ \text { Total } & 0 & 8 & 5 & 14 & 10 & 10 & 11 & 15 & 7 & 5 & 8 & 9 & 8\end{array}$

(b)

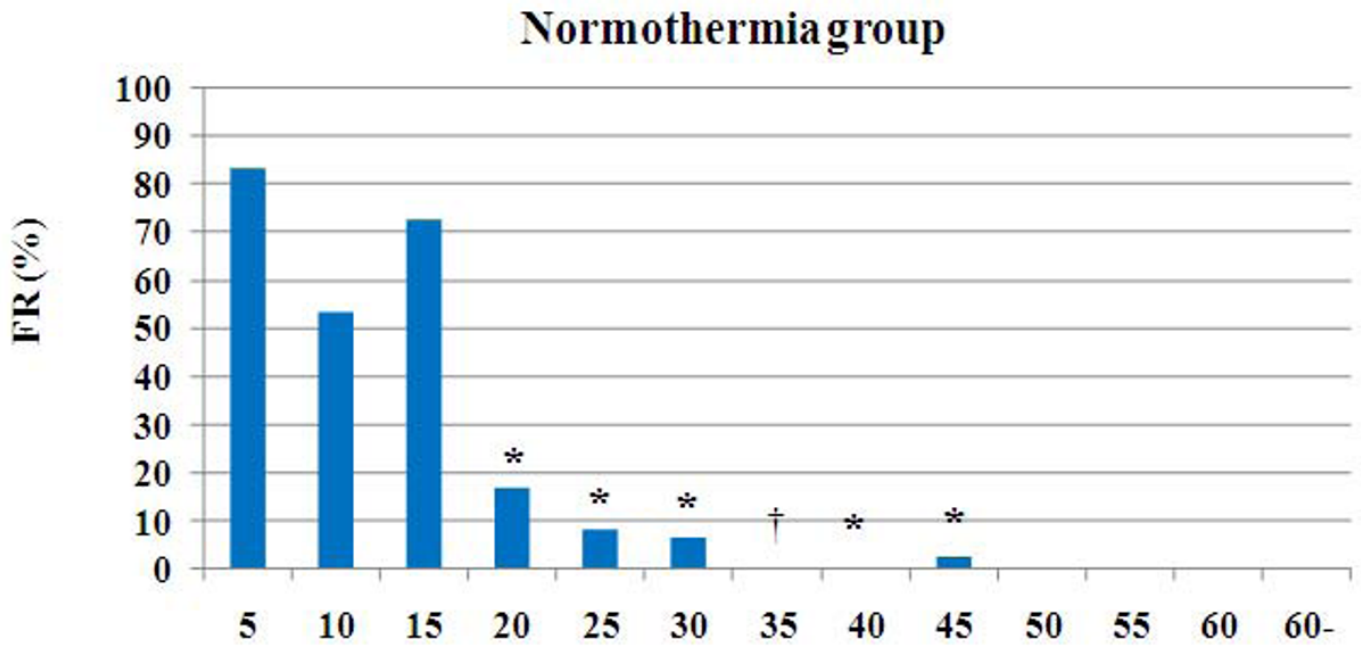

No. of patients

CPA-ROSC (min)

$\begin{array}{clllllllllllll}\text { FR } & 10 & 8 & 16 & 3 & 1 & 1 & 0 & 0 & 1 & 0 & 0 & 0 & 0 \\ \text { Total } & 12 & 15 & 22 & 18 & 12 & 15 & 13 & 19 & 42 & 28 & 21 & 21 & 52\end{array}$

Figure 2 Rate of favorable neurological outcome. The rate of favorable neurological outcome (FR) by the time interval from collapse to return of spontaneous circulation (CPA-ROSC) every 5 minutes in (a) the hypothermia group and (b) the normothermia group. *The rate of FR in the hypothermia group was higher than that in the normothermia group $(P<0.05){ }^{\dagger}{ }^{\dagger}$ There was a trend toward a higher rate of FR in the hypothermia group than in the normothermia group $(0.05<P<0.10)$. 
(a)

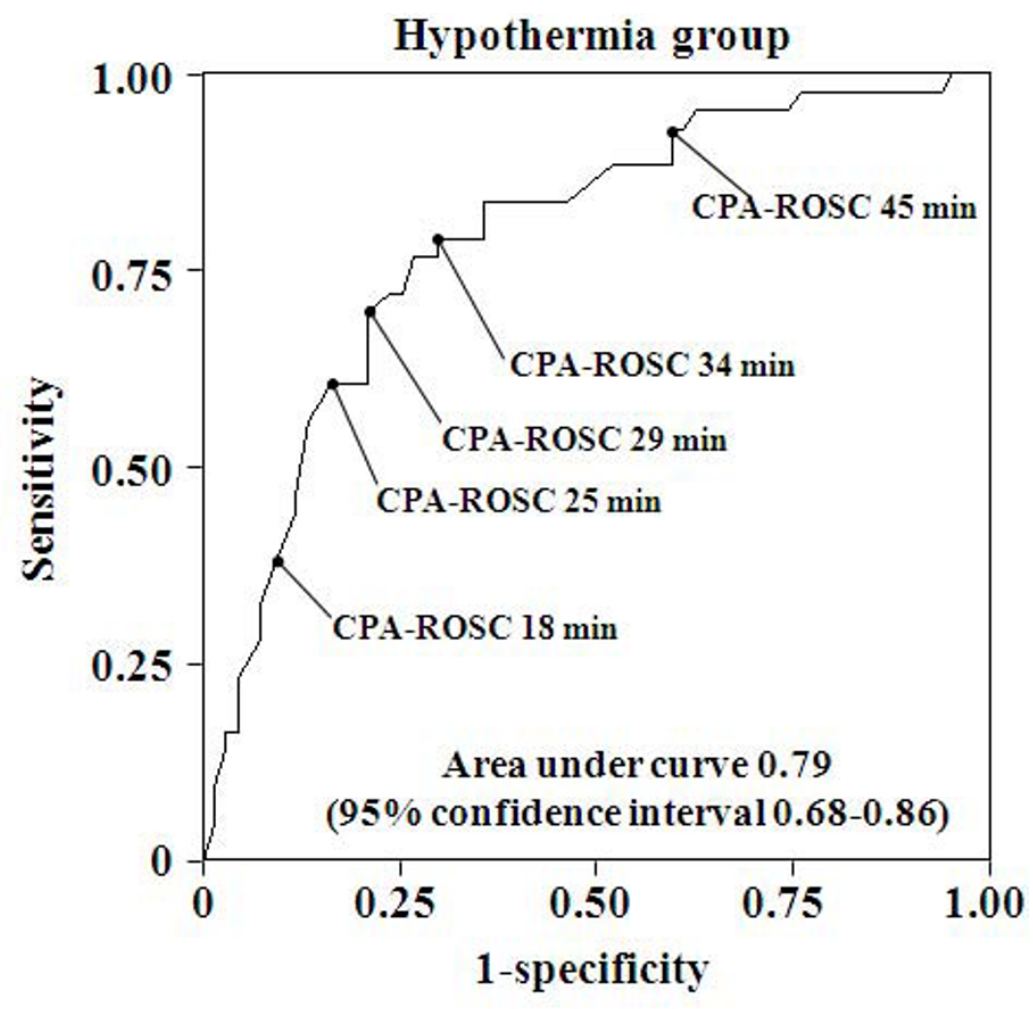

(b)

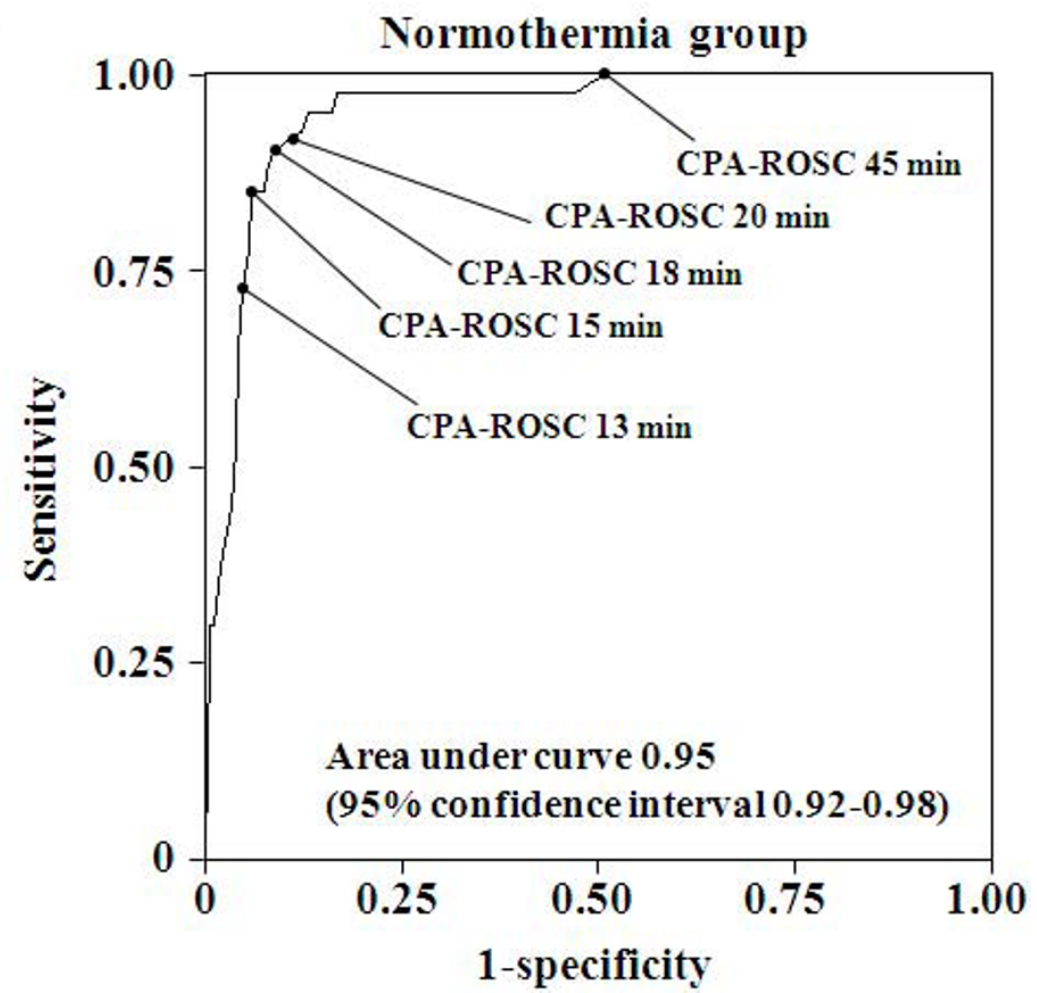

Figure 3 Time interval from collapse to return of spontaneous circulation predicting favorable neurological outcome. Receiveroperating characteristic curves for predicting a favorable neurological outcome in (a) the hypothermia group and (b) the normothermia group. CPA-ROSC, time interval from collapse to return of spontaneous circulation. 
Table 4 Cut-off values for CPA-ROSC and diagnostic accuracy

\begin{tabular}{|c|c|c|c|c|c|}
\hline CPA-ROSC & Sensitivity & Specificity & Positive predictive value & Negative predictive value & Accuracy (\%) \\
\hline \multicolumn{6}{|c|}{ Hypothermia group } \\
\hline 18 minutes & 37 (28 to 46$)$ & 91 (86 to 96$)$ & 73 (65 to 81$)$ & 69 (60 to 78$)$ & 70 \\
\hline 25 minutes & $60(51$ to 69$)$ & 84 (77 to 91$)$ & 70 (61 to 79$)$ & 77 (69 to 85$)$ & 74 \\
\hline 29 minutes & $70(61$ to 79$)$ & 79 (71 to 87$)$ & 68 (59 to 77$)$ & 80 (73 to 87 ) & 75 \\
\hline 34 minutes & 79 (71 to 87$)$ & 70 (61 to 79$)$ & 63 (54 to 72 ) & 84 (77 to 91 ) & 74 \\
\hline 45 minutes & 93 (88 to 98 ) & 40 (31 to 49$)$ & 50 (41 to 59$)$ & 90 (84 to 96$)$ & 61 \\
\hline 65 minutes & 100 & 4 (1 to 8$)$ & 40 (31 to 49$)$ & 100 & 42 \\
\hline \multicolumn{6}{|c|}{ Normothermia group } \\
\hline 13 minutes & 73 (68 to 78 ) & 95 (92 to 98$)$ & 71 (66 to 76$)$ & 96 (94 to 98 ) & 92 \\
\hline 15 minutes & 85 (81 to 89$)$ & 94 (91 to 97 ) & 69 (64 to 74$)$ & 98 (96 to 99$)$ & 93 \\
\hline 18 minutes & 90 (87 to 93 ) & 91 (88 to 94 ) & 62 (56 to 68) & 98 (96 to 99) & 91 \\
\hline 20 minutes & 92 (89 to 95$)$ & 88 (84 to 92 ) & 55 (49 to 61) & 99 (98 to 99) & 89 \\
\hline 45 minutes & 100 & 49 (43 to 55$)$ & 24 (19 to 29$)$ & 100 & 56 \\
\hline
\end{tabular}

Data presented as mean (95\% confidence interval) (\%). Time interval from collapse to return of spontaneous circulation (CPA-ROSC) cut-off value of 29 minutes in the hypothermia group and 15 minutes in the normothermia group had the highest combined sensitivity and specificity, with accuracies of $75.4 \%$ and $92.8 \%$, respectively.

As there is not enough blood flow to maintain the metabolism of organs in cardiac arrest patients, despite chest compression, the organs experience ischemic damage from the time of collapse to ROSC [19]. Furthermore, cardiac arrest triggers neuronal death and inflammation, as well as mitochondrial dysfunction, oxidative stress, altered signal transduction and programmed cell death, which are implicated in delayed injury after reperfusion. It has been suggested that the longer the CPA-ROSC, the greater the damage to organs, including the brain [20]. We showed that MTH may protect organs from these delayed injuries. We also showed that the rate of favorable neurological outcome in OHCA patients with a CPA-ROSC greater than 15 minutes was terrible, but was extended to 30 minutes or more in patients treated with hypothermia. MTH may protect organs from delayed injury, but the no perfusion or low perfusion state is longer, and damage of organs may be too severe for patients to return to their former lifestyle. The metabolic phase of the three-phase model explains these 15 minutes well [20].

The International Liaison Committee on Resuscitation has issued guidelines for treatment with MTH [21]. Because of the human resources and costs associated with $\mathrm{MTH}$, the criteria for treatment are different in each hospital $[3,4,8,10]$. The type of patients who can resume their former lifestyle without MTH has not been discussed. The results of the present study suggest that MTH may be more beneficial in patients with a CPAROSC greater than 15 minutes and a negative predictive value of $100 \%$ than in those with a CPA-ROSC of 45 minutes in OHCA patients without MTH. We suggest that comatose survivors of cardiac arrest of cardiac origin with a CPA-ROSC greater than 15 minutes must be treated with MTH. On the contrary, the neurological outcome of patients with a CPA-ROSC less than 15 minutes is likely to be similar with or without MTH. This does not, however, mean that OCHA patients with a CPA-ROSC less than 15 minutes should not be treated with MTH. Our study investigated only the neurological outcomes at the time of hospital discharge, and so performing MTH to protect mild neurological or organ damage should be permitted.

In our study, the CPA-ROSC of 65 minutes in the hypothermia group and of 45 minutes in the normothermia group had a negative predictive value of $100 \%$. These values may be the present points of no return for CPR in the present clinical settings. Our study showed that the shorter the CPA-ROSC, the higher the ratio of favorable neurological outcome. Cardiac arrest patients should be treated in a manner that achieves ROSC as soon as possible to obtain a better outcome.

\section{Study limitations}

Our study was not double-blind or randomized and had the inherent limitations of any single-centre retrospective investigation. The present study was prone to biases related to unmeasured factors. We did, however, use multivariate and propensity analyses to carefully match patients in an effort to eliminate bias. It was difficult for us to estimate the time of collapse of cardiac arrest patients correctly, so we enrolled only the witnessed cardiac arrest patients in this study. CPR guidelines were changed during the study period, which might affect the outcomes. We attempted to adjust for this effect with the additional covariate of admission after 2006 [12]. Although we found statistically significant differences 
(a)

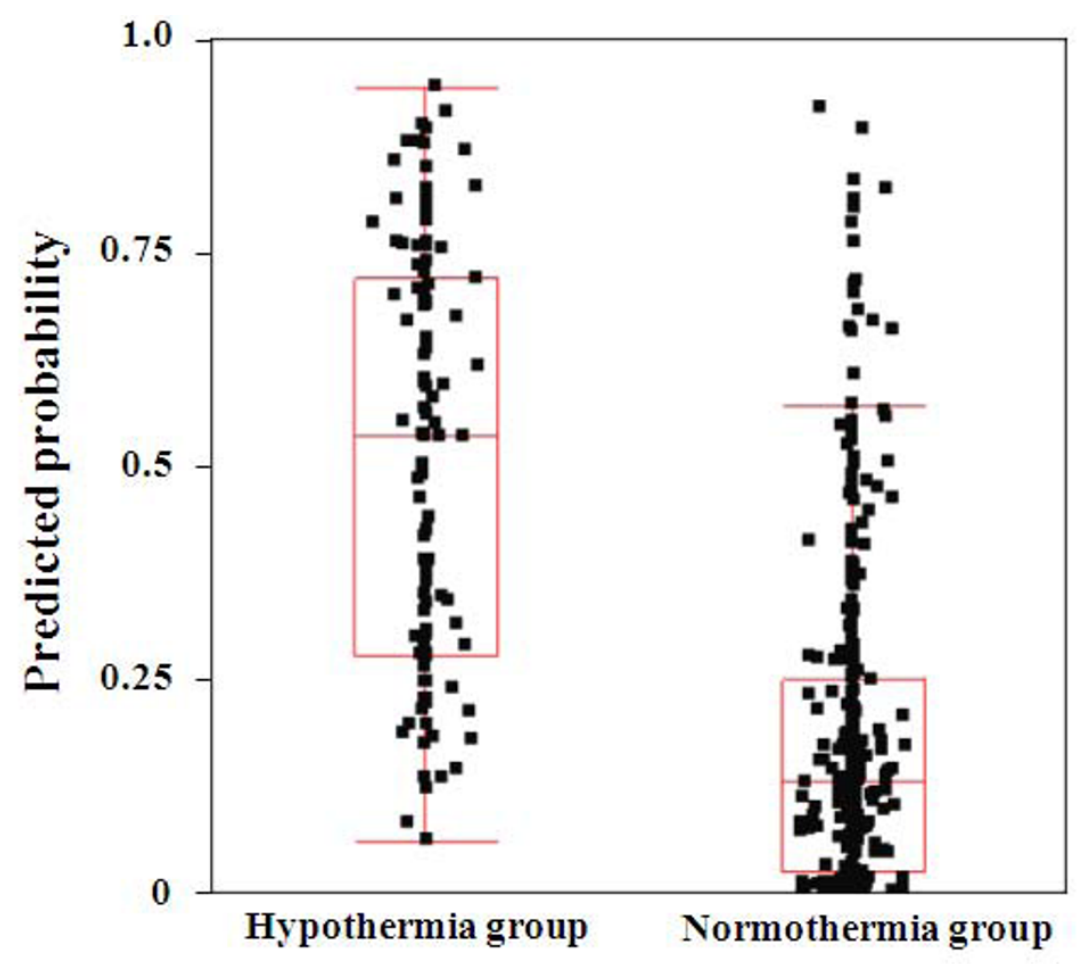

(b)

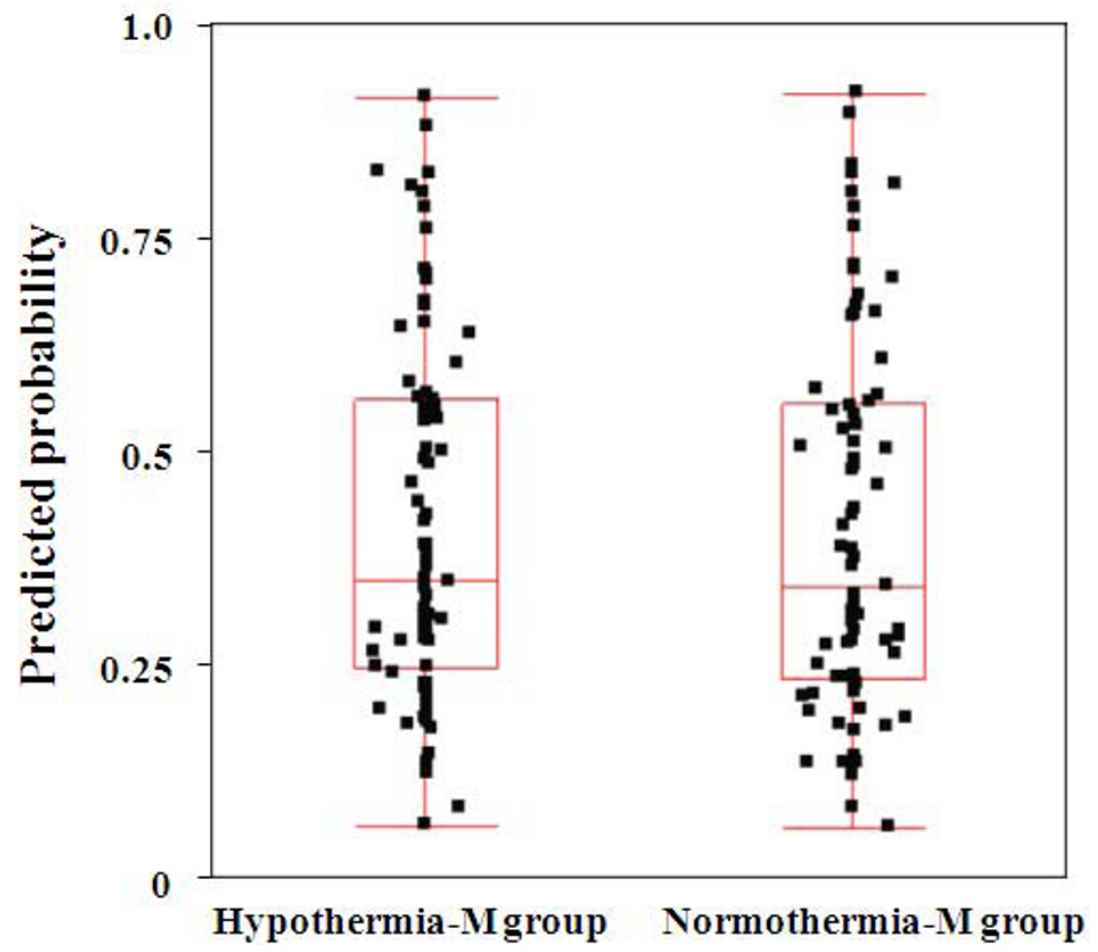

Figure 4 Distribution of propensity scores. Distribution of propensity scores (a) in the hypothermia and normothermia groups and (b) in the matched hypothermia-M and normothermia-M groups. 
Table 5 Patient characteristics and outcomes of propensity-matched patients

\begin{tabular}{|c|c|c|c|}
\hline & $\begin{array}{l}\text { Hypothermia-M group }(n= \\
\text { 79) }\end{array}$ & $\begin{array}{l}\text { Normothermia-M group }(n= \\
\text { 79) }\end{array}$ & $\begin{array}{l}P \\
\text { value }\end{array}$ \\
\hline Age (years) & 60 (49 to 72$)$ & $61(50$ to 71$)$ & 0.62 \\
\hline Male gender & $62(78)$ & $55(70)$ & 0.20 \\
\hline $\begin{array}{l}\text { Pittsburgh overall performance category scale } 1 \text { before index cardiac } \\
\text { arrest }\end{array}$ & $78(99)$ & $79(100)$ & $>0.99$ \\
\hline Initial rhythm & & & 0.72 \\
\hline Ventricular fibrillation & $23(29)$ & $25(32)$ & \\
\hline Pulseless electrical activity & $35(44)$ & $30(38)$ & \\
\hline Asystole & $21(27)$ & $24(30)$ & \\
\hline Bystander cardiopulmonary resuscitation & $42(53)$ & $37(47)$ & 0.43 \\
\hline $\begin{array}{l}\text { Time interval from collapse to start of cardiopulmonary resuscitation } \\
\text { (minutes) }\end{array}$ & $8(1$ to 12$)$ & $5(1$ to 10$)$ & 0.29 \\
\hline Time interval from collapse to return of spontaneous circulation (minutes) & 35 (22 to 49$)$ & $39(14$ to 50$)$ & 0.86 \\
\hline Hypertension & $36(46)$ & $25(32)$ & 0.07 \\
\hline Diabetes mellitus & $23(29)$ & $16(20)$ & 0.20 \\
\hline Previous history of heart disease & $31(39)$ & $20(25)$ & 0.06 \\
\hline Previous history of myocardial infarction & $12(15)$ & $5(6)$ & 0.07 \\
\hline Previous history of chronic heart failure & $12(15)$ & $9(11)$ & 0.48 \\
\hline \multicolumn{4}{|l|}{ Cause of cardiac arrest } \\
\hline Acute coronary syndrome & $35(44)$ & $20(25)$ & \\
\hline Old myocardial infarction & $8(10)$ & $7(9)$ & \\
\hline Cardiomyopathy & $8(10)$ & $4(5)$ & \\
\hline Spasm of coronary artery & $4(5)$ & $1(1)$ & \\
\hline Others & $18(23)$ & $14(21)$ & \\
\hline Unknown & $6(8)$ & $33(42)$ & \\
\hline Emergency coronary angiography & $44(56)$ & $20(25)$ & $<0.01$ \\
\hline Primary percutaneous coronary intervention & $23(29)$ & $9(11)$ & $<0.01$ \\
\hline Use of intra-aortic balloon pump & $44(56)$ & $15(19)$ & $<0.001$ \\
\hline Use of extracorporeal life-support & $21(27)$ & $5(6)$ & $<0.001$ \\
\hline Duration of hospital stay (days) & $16(4$ to 27$)$ & $1(0$ to 11$)$ & $<0.001$ \\
\hline Favorable neurological outcome & $24(30)$ & $23(29)$ & 0.86 \\
\hline Good cerebral performance & $24(30)$ & $23(29)$ & \\
\hline Coma or vegetative state & $6(8)$ & $1(1)$ & \\
\hline Dead & $49(62)$ & $55(70)$ & \\
\hline Thirty-day survival & $32(41)$ & $23(29)$ & 0.13 \\
\hline
\end{tabular}

Data presented as median (interquartile range) or $n(\%)$.

between the groups in our main cohort, we found no statistically significant differences between groups in our propensity-matched cohort. This difference might be caused by a sample that was small and may have been subject to type II error, and by good results for patients whose CPA-ROSC was less than 5 minutes in the normothermia-M group with no one whose CPA-ROSC was less than 5 minutes treated with hypothermia. We thought that clinical signs, such as neurological findings, gasping and spontaneous respiration, might be associated with the propensity score [22]. Although these clinical signs should have been recorded at fixed times after ROSC for proper analysis, we were unable to retrieve such data from the patients' medical records.

\section{Conclusions}

The CPA-ROSC is an independent predictor of neurological outcome in comatose survivors of OHCA. A CPAROSC longer than 15 minutes in the normothermia therapy group and longer than 30 minutes in the hypothermia therapy group was associated with low rates of favorable neurological outcome. MTH prolongs the CPA-ROSC, which may help comatose survivors of cardiac arrest obtain favorable neurological outcomes, 
(a)

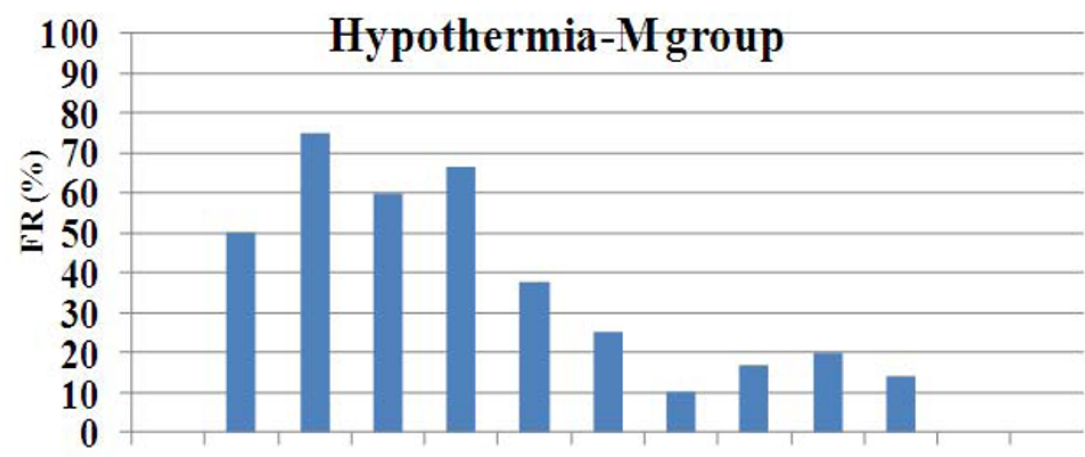

$\begin{array}{lllllllllllll}5 & 10 & 15 & 20 & 25 & 30 & 35 & 40 & 45 & 50 & 55 & 60 & 60-\end{array}$

No. of patients

CPA-ROSC (min)

$\begin{array}{clllllllllllll}\text { FR } & 0 & 2 & 3 & 6 & 4 & 3 & 2 & 1 & 1 & 1 & 1 & 0 & 0 \\ \text { Total } & 0 & 4 & 4 & 10 & 6 & 8 & 8 & 10 & 6 & 5 & 7 & 5 & 6\end{array}$

(b)

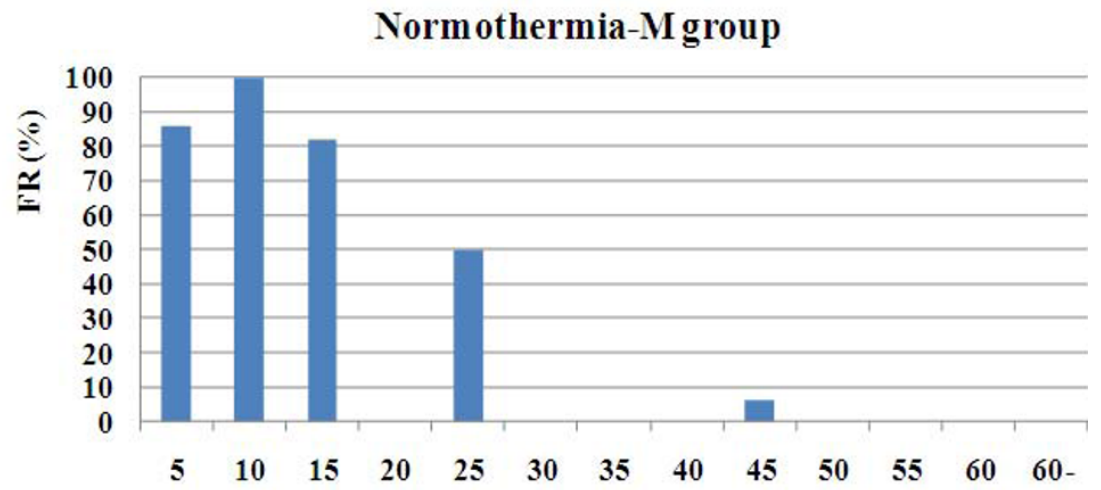

\section{No. of patients}

\section{CPA-ROSC (min)}

$\begin{array}{clllllllllllll}\text { FR } & 6 & 6 & 9 & 0 & 1 & 0 & 0 & 0 & 1 & 0 & 0 & 0 & 0 \\ \text { Total } & 7 & 6 & 11 & 2 & 2 & 0 & 4 & 8 & 16 & 4 & 7 & 3 & 9\end{array}$

Figure 5 Rate of favorable neurological outcome in the propensity-matched cohort. Plot representing the rate of favorable neurological outcome (FR) against the time interval from collapse to return of spontaneous circulation (CPA-ROSC) every 5 minutes in (a) the propensitymatched hypothermia-M group and (b) the normothermia-M group.

and is more beneficial in patients whose CPA-ROSC is greater than 15 minutes.

\section{Key messages}

- MTH is more beneficial in patients whose CPA-ROSC is greater than 15 minutes.

- Neurological outcome in patients treated with normothermia and hypothermia were similar in patients with a CPA-ROSC less than 15 minutes. - The CPA-ROSC is an independent predictor of neurological outcome in comatose survivors of cardiac arrest.
- A CPA-ROSC greater than 15 minutes in the normothermia therapy group and of 30 minutes in the hypothermia therapy group was associated with low rates of favorable neurological outcome.

\section{Abbreviations}

Cl: confidence interval; CPA-ROSC: time interval from collapse to return of spontaneous circulation; CPR: cardiopulmonary resuscitation; $\mathrm{MTH}$ : mild therapeutic hypothermia; OHCA: out-of-hospital cardiac arrest; ROSC: return of spontaneous circulation. 


\section{Competing interests}

The authors declare that they have no competing interests.

\section{Authors' contributions}

All authors participated in the design and coordination of the study and draft of the manuscript. All authors read and approved the final manuscript.

\section{Acknowledgements}

The authors appreciate the efforts of the coronary care unit, cardiology ward, emergency room and catheter laboratory nursing staff at Hiroshima City Hospital, which made the present study possible.

Received: 25 April 2010 Accepted: 16 August 2010

Published: 16 August 2010

\section{References}

1. Safar $P$ : Cerebral resuscitation after cardiac arrest: research initiatives and future directions. Ann Emerg Med 1993, 22:324-349.

2. SOS-KANTO Study Group: Cardiopulmonary resuscitation by bystanders with chest compression only (SOS-KANTO): an observational study. Lancet 2007, 369:920-926.

3. The Hypothermia after Cardiac Arrest Study Group: Mild therapeutic hypothermia to improve the neurologic outcome after cardiac arrest. $N$ Engl J Med 2002, 346:549-556.

4. Bernard SA, Gray TW, Buist MD, Jones BM, Silvester W, Gutteridge G, Smith K: Treatment of comatose survivors of out-of-hospital cardiac arrest with induced hypothermia. N Engl J Med 2002, 346:557-563.

5. Spaulding CM, Joly LM, Rosenberg A, Monchi M, Weber SN, Dhainaut JF, Carli P: Immediate coronary angiography in survivors of out-of-hospital cardiac arrest. N Engl J Med 1997, 336:1629-1633.

6. Garot P, Lefevre T, Eltchaninoff H, Morice MC, Tamion F, Abry B, Lesault PF, Le Tarnec JY, Pouges C, Margenet A, Monchi M, Laurent I, Dumas P, Garot J, Louvard Y: Six-month outcome of emergency percutaneous coronary intervention in resuscitated patients after cardiac arrest complicating ST-elevation myocardial infarction. Circulation 2007, 115:1354-1362.

7. Knafelj R, Radsel P, Ploj T, Noc M: Primary percutaneous coronary intervention and mild induced hypothermia in comatose survivors of ventricular fibrillation with ST-elevation acute myocardial infarction. Resuscitation 2007, 74:227-234.

8. Nagao K, Hayashi N, Kanmatsuse K, Arima K, Ohtsuki J, Kikushima K, Watanabe I: Cardiopulmonary cerebral resuscitation using emergency cardiopulmonary bypass, coronary reperfusion therapy and mild hypothermia in patients with cardiac arrest outside the hospital. J Am Coll Cardiol 2000, 36:776-783.

9. Polderman KH: Induced hypothermia and fever control for prevention and treatment of neurological injuries. Lancet 2008, 371:1955-1969.

10. Kagawa E, Inoue I, Kawagoe T, Ishihara M, Shimatani Y, Kurisu S, Nakama Y, Maruhashi T, Dai K, Matsushita J, Ikenaga H: History of diabetes mellitus as a neurologic predictor in comatose survivors of cardiac arrest of cardiac origin treated with mild hypothermia. Resuscitation 2009, 80:881-887.

11. Kagawa E, Inoue I, Kawagoe T, Ishihara M, Shimatani Y, Kurisu S, Nakama Y, Dai K, Otani T, Ikenaga H, Morimoto Y, Ejiri K, Oda N: Assessment of outcomes and differences between in- and out-of-hospital cardiac arrest patients treated with cardiopulmonary resuscitation using extracorporeal life support. Resuscitation 2010, 81:968-973.

12. ECC Committee, Subcommittees and Task Forces of the American Heart Association: 2005 American Heart Association Guidelines for Cardiopulmonary Resuscitation and Emergency Cardiovascular Care. Circulation 2005, 112:IV1-IV203.

13. Chen YS, Yu HY, Huang SC, Lin JW, Chi NH, Wang CH, Wang SS, Lin FY, Ko WJ: Extracorporeal membrane oxygenation support can extend the duration of cardiopulmonary resuscitation. Crit Care Med 2008, 36:2529-2535.

14. Hosmane VR, Mustafa NG, Reddy VK, Reese CLt, DiSabatino A, Kolm P, Hopkins JT, Weintraub WS, Rahman E: Survival and neurologic recovery in patients with ST-segment elevation myocardial infarction resuscitated from cardiac arrest. J Am Coll Cardiol 2009, 53:409-415.

15. Cummins RO, Chamberlain DA, Abramson NS, Allen M, Baskett PJ, Becker L, Bossaert L, Delooz HH, Dick WF, Eisenberg MS, Evans TR, Holmberg S, Kerber R, Mullie A, Ornato JP, Sandoe E, Skulberg A, Tunstall-Pedoe H,
Swanson R, Thies WH: Recommended guidelines for uniform reporting of data from out-of-hospital cardiac arrest: the Utstein Style. A statement for health professionals from a task force of the American Heart Association, the European Resuscitation Council, the Heart and Stroke Foundation of Canada, and the Australian Resuscitation Council. Circulation 1991, 84:960-975.

16. Jennett $B$, Bond $\mathrm{M}$ : Assessment of outcome after severe brain damage. Lancet 1975, 1:480-484

17. Chen YS, Lin JW, Yu HY, Ko WJ, Jerng JS, Chang WT, Chen WJ, Huang SC, Chi NH, Wang CH, Chen LC, Tsai PR, Wang SS, Hwang JJ, Lin FY: Cardiopulmonary resuscitation with assisted extracorporeal life-support versus conventional cardiopulmonary resuscitation in adults with inhospital cardiac arrest: an observational study and propensity analysis. Lancet 2008, 372:554-561.

18. The Comprehensive R Archive Network. [http://cran.r-project.org].

19. White BC, Grossman LI, O'Neil BJ, DeGracia DJ, Neumar RW, Rafols JA, Krause GS: Global brain ischemia and reperfusion. Ann Emerg Med 1996, 27:588-594.

20. Weisfeldt ML, Becker LB: Resuscitation after cardiac arrest: a 3-phase time-sensitive model. JAMA 2002, 288:3035-3038.

21. Nolan JP, Morley PT, Vanden Hoek TL, Hickey RW, Kloeck WGJ, Billi J, Bottiger BW, Okada K, Reyes C, Shuster M, Steen PA, Weil MH, Wenzel V, Carli P, Atkins D: Therapeutic hypothermia after cardiac arrest: an advisory statement by the Advanced Life Support Task Force of the International Liaison Committee on Resuscitation. Circulation 2003, 108:118-121

22. Young GB: Clinical practice. Neurologic prognosis after cardiac arrest. $N$ Engl J Med 2009, 361:605-611.

\section{doi:10.1186/cc9225}

Cite this article as: Kagawa et al: Who benefits most from mild therapeutic hypothermia in coronary intervention era? A retrospective and propensity-matched study. Critical Care 2010 14:R155.

\section{Submit your next manuscript to BioMed Central and take full advantage of:}

- Convenient online submission

- Thorough peer review

- No space constraints or color figure charges

- Immediate publication on acceptance

- Inclusion in PubMed, CAS, Scopus and Google Scholar

- Research which is freely available for redistribution
Ciomed Central 